\title{
$X$ Chromatin inactivation in Menopause: A study on Hindu caste Bengalee population
}

\author{
Koyel Mukherjee ${ }^{1}$, Diptendu Chatterjee ${ }^{2}$, Arup Ratan Bandyopadhyay ${ }^{3}$ \\ ${ }^{1}$ Assistant Professor, Department of Anthropology, Haldia Govt. College, Midnapore, West Bengal, India, ${ }^{2}$ Assistant \\ Professor, ${ }^{3}$ Professor, Department of Anthropology, University College of Science, Technology \& Agriculture, University \\ of Calcutta. 35, Ballygunge Circular Road, Kolkata - 700019, West Bengal, India
}

A B S TR A C T

Background: Menopause being a physiologic event and eventually the prime time to perform risk assessment of chronic diseases and initiate preventive health measures. Previous studies reported, later menopause is independently associated to increased risk of breast and endometrial cancer. The menopausal status is determined and influenced by intrinsic factors. Majority of the studies on menopause from Indian context, especially on Bengalee Hindu Caste population confined to socio demographic issues, attitudes, problems and quality of life. However, relatively little work is attempted to unravel the complex interplay of genetics and epigenetic mechanisms, the effect on menopause. In this background it seems to be an urgent need to understand menopause status objectively, to approach the interplay of genetics and epigenetic mechanisms of menopausal status by $\mathrm{X}$ chromatin inactivation. Aims and Objective: Best of the knowledge it is the first attempt to evaluate the prevalence of $X$ chromatin inactivation in menopausal women among Bengalee Hindu Caste population. Materials and Methods: Sex chromatin inactivation was evaluated from 100 each pre and post menopausal women from the buccal smear of each individuals. After fixation and staining of altogether 20000 (twenty thousand) cells were scanned from the Bengalee Hindu Caste for a comparison of menopausal women and their menarcheal counterparts. Results: Result demonstrated significantly decreased $(P<0.001)$ prevalence of $X$ chromatin inactivation sites among the menopausal females in comparison to their menarcheal women counterpart. Conclusion: The present study vindicated possible association between the presence of sex hormone receptors and the prevalence of sex chromatin and also envisaged the role of $\mathrm{X}$ chromatin inactivation for early prognosis of menopause.

Key words: Menopause, X chromatin inactivation, Bengalee Hindu Caste females

\section{Access this article online}

Website:

http://nepjol.info/index.php/AJMS DOI: 10.3126/ajms.v9i3.19434

E-ISSN: 2091-0576

P-ISSN: 2467-9100

\section{INTRODUCTION}

The transition from the reproductive to the nonreproductive phase is the consequence of attenuation in the female hormonal production by the ovaries. These hormonal changes eventually make the women in complex phases disrupting the sense of well-being due to the impact on different tissues. Abundant physical and psychological symptoms have been recognized to the hormonal changes of menopause which varies according to ethnicity, culture, and region. ${ }^{1}$ Worldwide studies on menopause reported the women of developing countries attain menopause at an earlier age. ${ }^{2}$ This biological event has important cultural, social, and epidemiological implications and hence attention towards understanding the age variations in the timing of the menopausal event was subject of research towards multidisciplinary relevance. Nevertheless, both early and delayed menopause has been found to be associated with the greater concern towards gradual, asymptomatic development degenerative conditions which may lead to significant morbidity and mortality. There is a need for further consideration of associations between early life factors and other markers of reproductive health, such as fertility and gynecological disorders. The study of reproductive health would benefit from an integrated approach covering the whole life course. In different

Address for correspondence:

Arup Ratan Bandyopadhyay, Department of Anthropology, University College of Science, Technology \& Agriculture,

University of Calcutta 35, Ballygunge Circular Road, Kolkata - 700019, West Bengal, India.

Mobile: +91-9432316126 E-mail: abanthro@caluniv.ac.in (C) Copyright AJMS 
populations, age at menopause may differ and various factors can contribute to an early or later initiation, including genetic factors, environmental exposures, healthrelated and socio-demographic factors. ${ }^{3}$ However, evidence of continuity in reproductive health across the life course indicates that for some women, the probable lifelong burden of poor reproductive health. For example, women having early menarche are more likely to have menstrual problems; ${ }^{4}$ eventually, those with menstrual problems are more likely to experience gynecological problems ${ }^{5}$ and sub-fertility, which have been associated with earlier menopause. ${ }^{6}$ A number of biological and social trails may be operating across the life course that account for this continuity. These include variation in lifelong exposure or susceptibility to estrogen or other hormonal mechanisms, which may in turn reflect in personality and psychological susceptibility and continuity in the socioeconomic environment. Each of these perhaps influence and be influenced by body composition and diet as well. These results suggest that the study of reproductive health would benefit from an integrated approach covering the whole life course, rather than each reproductive health outcome being studied in isolation ${ }^{1}$. In this context, issues regarding menarcheal age, earlier study ${ }^{7}$ on Bengalee Hindu Caste population comprehensively revealed biological and social trails in terms of significant association with nutritional status and age at menarche and per capita income as well. Similarly, regarding the socio economic aspects the menopausal among the Bengalee Hindu caste population ${ }^{8}$ reported lower employment status and significantly higher menopausal age among the rural women compared to that of the urban women. Furthermore, subsequent study on the menopause from the Bengalee Hindu Caste population of West Bengal, focusing only socio demographic variables and eventually yielded diverse results for example age at menarche, duration of breastfeeding of the last child, and age at first pregnancy discriminate the different menopausal age groups. ${ }^{9}$ In addition to that study on Bengalee Hindu Caste females reported socio-demographic and reproductive factors seem to be significantly associated with menopausal problems and residential status appears to be a confounder variable for menopausal problems as well. ${ }^{10} \mathrm{In}$ other words, studies among Bengalee Hindu caste women revealed no as such conclusive but variable findings. Study on menopausal symptoms and its correlates from tribe and Bengalee Hindu Caste population from West Bengal ${ }^{11}$ revealed significant difference with respect to the estrogen deficient menopausal problems and the concomitants to these problems, but without empirical research towards assay of estrogen status. Nevertheless, estrogen deficiency was one of the reasons for heavy or scanty menstrual discharge. ${ }^{12}$ But comprehensive global study ${ }^{2}$ suggested that age at menarche is mainly determined by extrinsic factors, such as living conditions, while age at menopause appears to be influenced by intrinsic factors, such as reproductive history. The most important determinants of age at natural menopause are considered to be factors that affect the duration of decline in ovarian follicle reserve such as number of primordial germ cells that migrate to the gonadal ridge during intrauterine life, Mitotic abilities of these cells until gestational age of approximately 1620 week, ${ }^{1}$ rate of follicular atresia in both intra- and extrauterine environments ${ }^{13,14}$ suggesting that early life factors may play an important role in influencing age at menopause.

It appears from the aforementioned studies that it is an urgent need to understand the menopausal status objectively, to avoid assorted and reiterated results pertaining to merely qualitative socio demographic context. Therefore, studies related to biological markers seem to be urgent at initial stage. From India, some scattered studies have focused on estimating age at menopause and menopausal symptoms. ${ }^{10}$ But the reports from Eastern India, particularly in the context of Bengalee Hindu Caste population has been taken up the main focus on correlates of menopause from socio demographic aspects to explain problems, attitude and quality of life. ${ }^{8,9,15,16}$ The results, however, demonstrated variable outcomes from the Bengalee Hindu Caste women such as, residential, literacy status, duration of breast feeding of child, duration of postmenopausal years, association of menopause-specific quality of life of women, along with inconsistency in bivariate and multivariate modeling, ${ }^{15}$ per capita monthly expenditure, age at menopause, years after menopause, and menopausal symptoms significantly predicted by attitude. However, relatively little work is attempted to unravel the complex interplay of genetics and epigenetic mechanisms, of menopause. ${ }^{1}$

Under this circumstance, the present study has been undertaken to find out the effect $\mathrm{X}$ chromatin inactivation on assessing the menopausal status in comparison to menarcheal status. During X chromosome inactivation (XCI), Xist RNA coats and silences one of the two X chromosomes in female cells. ${ }^{18}$ Chromatin remodeling guided by non-coding RNA (ncRNA) contributes mechanistically to the establishment of chromatin structure and to the maintenance of epigenetic memory and current review highlighted parallels between the establishment of a silent chromatin state mediated by siRNAs and long antisense ncRNAs. ${ }^{19}$ On the basis of this background, the present study, to best of the knowledge is the initial effort to evaluate the prevalence of sex chromatin among the menopausal women among the Bengalee Caste Hindu Females. 
Table 1: Prevalence of sex chromatin in menarcheal and menopausal females

\begin{tabular}{lcccc}
\hline Status & No. & No. of cells studied & Sex chromatin present (\%) & Sex chromatin absent (\%) \\
\hline Menarcheal & 100 & 10000 & 5860 & 4140 \\
& & & $(58.60)$ & $(41.40)$ \\
Menopausal & 100 & & 2948 & $7052^{*}$ \\
& & & $(29.48)$ & $(70.52)$ \\
\hline
\end{tabular}

${ }^{*} p<0.05$

\section{MATERIALS AND METHODS}

Sex chromatin inactivation was evaluated from 100 each from pre and post menopausal women from the buccal smear of each individual from the Bengalee Hindu Caste. Subsequently, 100 cells from each participants were scanned, thereby altogether 20000 (twenty thousand) cells were checked for $\mathrm{X}$ chromatin inactivation sites for the comparison of prevalence of $\mathrm{X}$ chromatin inactivation among the menopausal women and their menarcheal counterparts. The age range of pre-menopausal females was 22 to 24 years (mean age $23.28 \pm 3.38$ years) being in ovulation phase under the natural sex hormones, while the post-menopausal ( 50 - 56 years, mean age $46.22 \pm 3.30$ years) being in non-ovulation phase and under the physiological withdrawal of natural sex hormones. The present work has been approved by the Institutional (University of Calcutta) Ethical Committee (Ref. No. CU/BIOETHICS/ HUMAN/2304/2020). Moreover, before the work the participants appraised regarding the work and verbal consents were taken. Apparently healthy menstruating women who were unmarried and non contraceptive user having regular menstruating cycle were taken into the study. Women who reported 12 continuous months of amenorrhea, without a hysterectomy or other procedure that would have stopped their menses, were classified as naturally menopausal. Age at naturally menopausal was defined as the age at last menstrual period. ${ }^{20}$ After taking consent from the individuals, socio demographic information regarding age, age at menarche, menarcheal status, socio-economic status, contraceptive efforts etc. has been collected. Buccal smear of each individuals have been collected by sterile 6" foam-tip buccal cell collection swab (Epicenter, Tebu-bio) from the inside of the cheek. Fixation and staining was done following standard technique. ${ }^{21}$ For scanning optical microscopy (resolution $10 \times 40)$ the slides were DPX mounted by cover glass. Descriptive and inferential statistics have been utilized in appropriate place. Cut off was set as $\mathrm{p}=0.05$.

\section{RESULTS}

The present study attempted the prevalence of sex chromatin in pre and post menopausal females of Bengalee Caste Hindu females and the result is presented in Table 1.
Examination on prevalence of sex chromatin revealed significantly $(\mathrm{p}<0.001)$ decreased sex chromatin prevalence in menopausal females compared to that of menarcheal females. In females, FSH stimulates the growth of ovarian follicles, but not their complete maturation, and estrogen secretion. Secretion of FSH and LH becomes cyclical in the females at puberty. These hormones combine with intra nuclear cytosolic receptor proteins and form a complex, which interacts with DNA itself to stimulate transcription. However, the rapid Estrogen Receptor signaling provides a direct linkage between xenoestrogen-induced nuclear hormone receptor signaling and modulation of the epigenetic machinery during tissue development. ${ }^{22}$ Since, defining menopause not an event that limits women's psychological and physical capacities, but a natural part of aging, ${ }^{23}$ therefore, as one of the urgent needs the towards public health menopausal status seems to be an important task to ascertain with biological attributes of as far as practicable in the post genomic $\mathrm{era}^{24}$ to analyse cellular function ${ }^{1,18,19,22}$ which is speedy and accurate as the initial step rather than confined to socio demographic perspectives and other qualitative dimensions. The present study is found to be in consistency with earlier studies ${ }^{25,26}$ for utilization of $\mathrm{X}$ chromatin inactivation (Barr body) for determination of age.

\section{CONCLUSION}

Because of the alterations in natural sex hormones in pre menopausal and post menopausal state of females, the present study envisaged the possible role of $\mathrm{X}$ chromatin as a proxy measure for hormonal attribution to understand epigenetic machinery during tissue development.

\section{ACKNOWLEDGEMENTS}

Financial support from University of Calcutta [BI 65 (8 \&9) is acknowledged. Authors are grateful to the participants for their kind cooperation

\section{REFERENCES}

1. Mishra GD, Cooper R, Tom SE and Kuh D. Early life circumstances and their impact on menarche and menopause. Womens Health (Lond Engl) 2009; 5: 175-190. 
2. Thomas F, Renaud F, Benefice E, de Meeüs T and Guegan JF. International variability of ages at menarche and menopause, patterns and main determinants. Human Biology 2001; 73:271290.

3. Gold EB, Bromberger Y, Crawford S, Samuels S, Greendale G A, Harlow SD, et al. Factors Associated with Age at Natural Menopause in a Multiethnic Sample of Midlife Women. American Journal of Epidemiology 2001; 153: 865-874.

4. Hunter M. The south-east England longitudinal study of the climacteric and post-menopause. Maturitas 1992; 14:117-126.

5. Gardner J. Adolescent menstrual characteristics as predictors of gynaecological health. Annals of Human Biology 1983; 10:31-40.

6. Kok HS, van Asselt KM, van der Schouw YT, Grobbee DE, te Velde ER, Pearson PL, et al. Subfertility reflects accelerated ovarian ageing. Human Reproduction 2003; 18:644-648.

7. Ghosh J R, Basak S and Bandyopadhyay AR. A study on nutritional status among young adult Bengalee females of Kolkata: effect of menarcheal age and per capita income. Anthropologischer Anzieger 2009; 67:13-20.

8. Dasgupta D and Ray S. Menopausal Problems among Rural and Urban Women from Eastern India Journal of Social, Behavioral, and Health Sciences 2009; 3:20-33.

9. Dasgupta D, Pal B and Ray S. Factors that discriminate age at menopause: A study of Bengali Hindu women of West Bengal. American Journal of Human Biology 2015; 27:710-715.

10. Dasgupta D and Ray S. Vasomotor and urogenital problems at midlife: a study on rural and urban women in India. Annals of Human Biology 2015; 42: 268-275.

11. Dasgupta D, Karar P, Ray S and Ganguly N. Menopausal Symptoms and Its Correlates: A Study on Tribe and Caste Population of East India. Current Gerontological and Geriatric Research 2015; Article ID 984767, 7 pages

12. Sweeney BL, Dennis K and Desai A. Gynecologic and obstetric disorders: contraception, hormone replacement therapy and endometriosis. In: M. Lee and A. Desai, eds. Gibaldi's Drug Delivery Systems in Pharmaceutical Care American Society of HealthSystem Pharmacists, Bethesda, Md, USA, 2007 pp. 321-344.

13. Ginsberg J. What determines the age at the menopause? British Medical Journal 1991; 302:1288-1289.
14. Aydos SE, Elhan $\mathrm{AH}$ and Tukun $\mathrm{A}$. Is telomere length one of the determinants of reproductive life span? Archives of Gynecology and Obstetrics 2005; 272:113-116.

15. Som N, Roy $P$ and Ray S. Menopause-specific quality of life of a group of urban women, West Bengal India. Menopause International 2012; 18:99-105.

16. Dasgupta D and Ray S. Attitude toward menopause and aging: a study on postmenopausal women of West Bengal. Journal of Women \& Aging 2013; 25:66-79.

17. Mukherjee K, Burman M and Bandyopadhyay AR. Prevalence of Sex Chromatin in Bengalee Caste Hindu Females: Study on Interrelationship of Hormones. International Journal of Physical and Social Sciences 2014; 4(11): 68-76.

18. Shen $Y$, Matsuno $Y$, Fouse $S D$, Rao $N$, Root $S, X u R$, et al. $X$-inactivation in female human embryonic stem cells is in a nonrandom pattern and prone to epigenetic alterations. Proceedings of National Academy of Science 2008; 105: 4709-4714.

19. Malecová B and Morris KV. Transcriptional gene silencing through epigenetic changes mediated by non-coding RNAs Current Opinion of Molecular Theory 2010; 12: 214-222.

20. WHO Technical Report Geneva, Switzerland: World Health Organization; World Health Organization. Research on menopause 1996; series.No.866

21. Mittal T, Saralaya KM, Kuruvilla A and Achary C. Sex determination from buccal mucosa scrapes. Int Journal of Legal Medicine 2009; 5: 437-440.

22. Bredfeldt TG, Greathouse KL, Safe SH, Hung MC, Bedford MT and Walker CL. Xenoestrogen-induced regulation of EZH2 and histone methylation via estrogen receptor signaling to PI3K/AKT. Molecular Endocrinology 2010; 24:993-1006.

23. McCrea F. The politics of menopause: the discovery of a deficiency disease. Soc Prob 1983; 13: 111-113.

24. Vicki Brower. Proteomics: biology in the post-genomic era. EMBO Rep 2001; 2: 558-560.

25. Sahu P, Pal SK and Rana A. Determination of Age and Development of Barr body in Root Sheath Cells of Human Females. JFSCI 2017, 5: MS.ID.5556672017

26. Singh $\mathrm{H}$, Aggarwal OP and Rashid AF. Use of Hair Root Sheath for Barr body Determination. JIndAcad Foren Med 2011, 33: 143-144.

\section{Authors Contribution:}

KM- Collected Data, Statistically analyzed and interpreted; DC- Reviewed the literature, helped in preparing first draft of manuscript; ARB- Concept and design of the study, critical revision of the manuscript

Work attributed to:

Department of Anthropology, University of Calcutta, Kolkata

Orcid ID:

Prof. Arup Ratan Bandyopadhyay- (i) http://orcid.org/0000-0003-3119-0022

Source of Support: University of Calcutta [BI 65 (8 \&9), Conflict of Interest: None declared. 